\title{
IDENTIDADES JUVENILES Y TRAYECTORIAS SOCIALES EN BARRIOS CERRADOS DE Argentina. El CASO de Nordelta
}

\author{
MARCos MUTUVERRÍA ${ }^{1}$
}

\begin{abstract}
RESUMEN
El artículo analiza la construcción identitaria en jóvenes de Nordelta a partir del estudio de las trayectorias sociales, la vida en un barrio cerrado y la incidencia de la movilidad en sus prácticas socioculturales cotidianas. Se trata de un nuevo estudio que dialoga con el campo de investigaciones sobre la cuestión juvenil, poniendo foco en jóvenes de sectores de clase media alta, particularmente en residentes del barrio cerrado Nordelta, paradigmático en la zona norte del Área Metropolitana de Buenos Aires, Argentina. Se muestran percepciones en torno a trayectorias zigzagueantes, presencia de estigmatizaciones, análisis de movilidades y estrategias de aprovechamiento del tiempo en relación con las distancias prolongadas.
\end{abstract}

PALABRAS CLAVES: JUVENTUD, IDENTIDAD, TRAYECTORIA SOCIAL.

${ }^{1}$ Doctor en Ciencias Sociales (UNGS-IDES). Miembro del Laboratorio de Estudios en Cultura y Sociedad (LECyS) en FTS-UNLP-CONICET, Argentina. Correo electrónico:marcosmutuverria@gmail.com 


\title{
IDENTIDADES JUVENIS E TRAJETÓRIAS SOCIAIS EM BAIRROS FECHADOS DA ARGENTINA. O CASO DE NORDELTA
}

\begin{abstract}
RESUMO
O artigo analisa a construção identitária em jovens de Nordelta a partir do estudo das trajetórias sociais, a vida em um bairro fechado, e a incidência da mobilidade em suas práticas socioculturais cotidianas. Este é um novo estudo que dialoga com o campo de pesquisa sobre a questão juvenil, focando em jovens de setores da classe média alta, particularmente em moradores do bairro fechado de Nordelta, paradigmático na zona norte da Área Metropolitana de Buenos Aires, Argentina. São apresentadas percepções em torno das trajetórias em zigue-zague, presença de estigmatização, análise de mobilidade e estratégias de uso do tempo em relação a longas distâncias.
\end{abstract}

PALAVRAS-CHAVE: JUVENTUDE, IDENTIDADE, TRAJETÓRIA SOCIAL.

\section{YOUTH IDENTITIES AND SOCIAL TRAJECTORIES IN GATED COMMUNITIES OF ARGENTINA. THE CASE OF NORDELTA}

\begin{abstract}
The article analyses the identity construction of young people in Nordelta, from the study of their social trajectories, their lives in a gated community and the incidence of mobility in their daily socio-cultural practices. This new study converses to the youth-related research field, focusing on upper-middle class young people, particularly residents of Nordelta gated community, considered as a paradigm in the north zone of Buenos Aires Metropolitan Area, Argentina. Perceptions towards zigzagging trajectories, presence of stigmatizations, mobility analyses and time usage strategies in relation to long distances are shown.
\end{abstract}

KEYWORDS: YOUTH, IDENTITY, SOCIAL TRAJECTORY. 


\section{INTRODUCCIÓN}

El objetivo de este artículo es analizar la construcción identitaria en jóvenes de Nordelta a partir del estudio de las trayectorias sociales, la vida en un barrio cerrado y la incidencia de la movilidad en sus prácticas socioculturales cotidianas ${ }^{2}$. El sentido de la investigación reposa en dos intereses. Por un lado, se trata de un nuevo estudio que dialoga con el campo de investigaciones sobre la cuestión juvenil, en este caso en relación con jóvenes de sectores de clase media alta. Por otra parte, focaliza en los modos de habitar los barrios cerrados, eligiendo el caso paradigmático de Nordelta en la zona norte del Área Metropolitana de Buenos Aires, Argentina.

\section{ANTECEDENTES}

Este artículo presenta resultados dentro del campo de los estudios en juventudes en Argentina, y por ello se definen ideas en relación con la condición juvenil y desde qué posicionamiento se analizan los jóvenes que forman parte del mismo. La juventud es considerada como una condición social, lo cual implica entender su morfología, en parte, desde la percepción, vivencia y caracterización de quienes se definen como jóvenes, inscribiendo la lectura de sus prácticas y consideraciones en los contextos histórico-culturales específicos en los que se producen. Se piensa la multiplicidad, pluralidad y heterogeneidad en las formas de ser jóvenes, y no se adscribe en pensar la juventud como un momento de la vida, ya que establecer una demarcación precisa de su alcance a partir del dato biológico que representa la edad cronológica llevaría a determinaciones homogeneizantes.

En coincidencia con Levi y Schmitt (1996), las demarcaciones etarias cronológicas como «naturalmente» delimitantes de la condición juvenil son producto de procesos socioculturales históricos, como muestran los estudios realizados sobre ciclos de la vida. Resulta importante analizar el procesamiento sociocultural de la edad a partir de identificar los sistemas de clasificación etarios puestos en uso. Se asume una visión de los jóvenes como seres en relación (Chaves, 2005 y 2010) y como actores sociales completos con posible

${ }^{2}$ El artículo presenta resultados parciales del proyecto de investigación titulado «La construcción identitaria en jóvenes de Nordelta: un estudio de trayectorias sociales y modos de habitar el territorio», desarrollado durante 2018 y 2019 en la Universidad de San Isidro, zona norte de la Provincia de Buenos Aires, Argentina. 
abordajes analíticos desde una triple complejidad: contextual (espacial e históricamente situada), relacional (conflictos y consensos) y heterogénea (diversidad y desigualdad).

Por otra parte, se piensa la utilidad del estudio de trayectorias sociales como disparador para el análisis, ya que indagar en la trayectoria significa ubicarse en el dinámico espacio social y visualizar las posiciones que van ocupando los sujetos, quienes recorren a lo largo de sus vidas un continuo de experiencias que van trazando itinerarios, a veces más previsibles, a veces más aleatorios (Bourdieu, 1988a), que se construyen simultánea y pluralmente en diversas dimensiones: familiar, social, laboral, educativa, política, cultural, religiosa.

En palabras de los investigadores chilenos Dávila y Ghiardo (2005), no importa analizar en particular la secuencia que forman las sucesivas fases de generación de nuevos individuos, sino las «posiciones estructurales y las disposiciones subjetivas que producen (en el sentido de "ser producto de" y "producir") los cambios de condición del joven» (p. 118). Las trayectorias sociales tienen un punto de inicio en el que se podrían definir el volumen y la estructura de los capitales ${ }^{3}$ con que cuenta cada persona, y prestar atención a los cambios que van sucediendo en los distintos campos en los que participa. Al momento de nacer, la familia aparece como un factor de relevancia, ya que de ella depende el «patrimonio» que «se recibirá» como capital heredado. Usando como metáfora la idea del «juego», la posición de origen dispone las cartas para jugar, incide en el lugar y la «fuerza» con que parte una trayectoria, y marca varios caminos posibles de ser recorridos (Dávila, Ghiardo y Medrano, 2005: 80). Es un «campo de los posibles» (Bourdieu, 1988b), a partir del cual un sujeto recibe un volumen determinado de «capital heredado» que posibilita un «haz de trayectorias» más o menos probables que conducen a unas posiciones más o menos equivalentes (1988b: 108). Esto se interpreta en un sentido que no le quita margen de acción al sujeto.

Para Bourdieu (1988a), la trayectoria representa un elemento importante que orienta las disposiciones de las personas para la acción, combinando dos

${ }^{3}$ Martin-Criado (1998) describe que Bourdieu distingue otras especies de capitales, además del económico, que suponen apropiación diferencial: «Un capital cultural (con subespecies, como el capital lingüístico), un capital escolar (capital cultural objetivado en forma de títulos escolares), un capital social (relaciones sociales movilizables para la obtención de recursos), un capital simbólico (prestigio)» ( $\mathrm{p}$. 73). 
efectos para explicar las prácticas y su correlación con el origen social: por una parte, el efecto de inculcación, ejercido directamente por la familia o por las condiciones de existencia originales, y por otra, el efecto de trayectoria social propiamente dicho, es decir, el que ejercen las experiencias de ascensión o de decadencia social sobre las disposiciones y las opiniones. La tarea de intentar comprender las vidas de los sujetos no sería del todo posible si se piensan sus trayectos de vida como una serie única y suficiente en sí de acontecimientos sucesivos. Por el contrario, las trayectorias - serie de las posiciones sucesivamente ocupadas por un mismo agente (o un mismo grupo) en un espacio en sí mismo en movimiento- están sometidas a continuas e «incesantes transformaciones» (Bourdieu y Passero, 1977: 82). En Argentina existen abordajes de las trayectorias juveniles en vínculo con lo educativo: Mayer (2007), Dombois (1998), Kaplan (2005), Briscioli (2009), entre otros; centrados en lo laboral: Jacinto (2010), Pérez, Deleo y Fernández Massi (2013), Freytes Frey (2009), entre otros; y uniendo trabajo y estudio (Miranda, 2008). Como se considera a los estudios de trayectorias sociales juveniles de manera diversa, pensar en las trayectorias como ámbitos fragmentados (familia, escuela, grupos de pares, trabajo, etc.) sería negar la interdependencia que hace a la constitución del sujeto, por eso se entiende una integralidad de clivajes en los espacios de socialización de los sujetos.

Se piensa a las identidades —en coincidencia con Stuart Hall y Du Gay (1996) - como aquellas construidas a partir del discurso y no fuera de él. Identidades producidas en lugares específicos, históricos e institucionales dentro de formaciones y prácticas específicamente discursivas. Esto sujeto al reconocimiento de que es solo en la relación con el «otro» - exterior constitutivo - donde las identidades pueden ser construidas (Derrida, 1981; Laclau, 1990; Butler, 1993).

Este análisis también dialoga con otras producciones sobre prácticas sociales en barrios cerrados de Argentina (Hernández, 2009; Janoschka, 2002; Malizia y Paolasso, 2009), en particular de la Provincia de Buenos Aires (Janoschka, 2006; Beltrán y Heredia, 2002; Segura y Chaves, 2019; Thuillier, 2005), sobre clases medias y altas (Dukuen y Kriger, 2016; Fuentes, 2015) y la socialización deportiva (Fuentes, 2019). 


\section{3. ¿POR QUÉ Nordelta?}

El Área Metropolitana de Buenos Aires (AMBA) está compuesta por localidades y barrios de la Ciudad de Buenos Aires y del Gran Buenos Aires. La zona norte del AMBA es reconocida socialmente por tener los countries y barrios privados más exclusivos de la provincia. El estudio de Ciccolella (2011) enmarca el AMBA en la RMBA (Región Metropolitana de Buenos Aires), delineado por anillos o cordones. La RMBA incluye las siguientes jurisdicciones: a) Ciudad Autónoma de Buenos Aires (CABA), con una población de 3.100 .000 habitantes; b) Gran Buenos Aires $\left(1^{\circ}\right.$ y $2^{\circ}$ cordón del conurbano), conformada por 25 partidos y una población que ronda los 9.000.000 de habitantes; y c) el resto de la RMBA o « $3^{\circ}$ cordón», compuesto por 15 partidos y una población que ronda los 3.700.000 habitantes (imágenes 1 y 2).

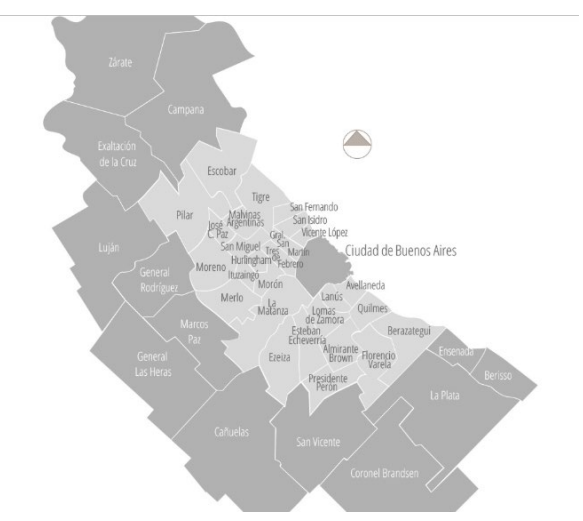

1) Región Metropolitana BA.

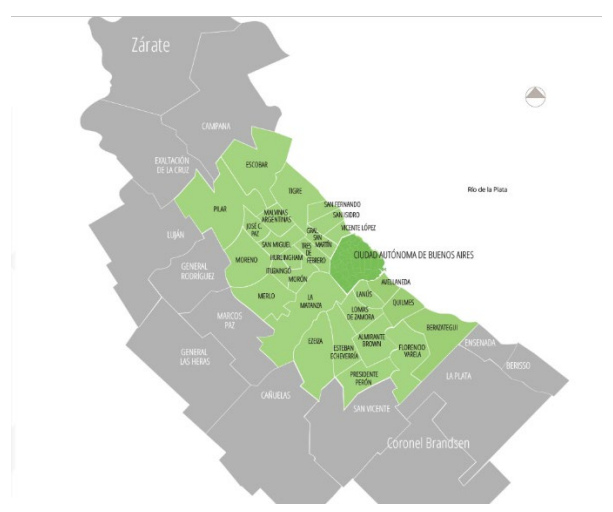

2) Área Metropolitana BA.

Nordelta -localidad del Partido de Tigre- resulta un caso paradigmático dentro de los barrios cerrados. Michael Janoschka (2006) realizó un estudio importante sobre sus orígenes y lo consideró el máximo exponente en los barrios cerrados de Argentina. Como parte de un análisis sobre el modelo de ciudades latinoamericanas, el autor consideró que el modelo predominante era el de segregación y división, con un marcado proceso de privatización con crecimiento urbano de forma celular. Es en este panorama donde se inscribe esta localidad como resultado de la relación de public-private-partnership dada en Argentina en la década de los 90. 
La creación de Nordelta (ver imagen 3) se comprende por el crecimiento económico que se produjo en los años 90 en la mayoría de los países de Latinoamérica que, en términos de Borsdorf e Hidalgo (2004), tendió a producir formas similares de asentamiento de la población, reforzando la construcción de un tipo de urbanizaciones con medidas de seguridad e idealización de la vida campestre. Ese desarrollo económico no se tradujo en prosperidad para toda la sociedad y significó un quiebre socioespacial en las ciudades, que se manifestó en la creciente diferenciación entre los grupos sociales. Creció la brecha entre pobres y ricos, y hubo un aumento del distanciamiento social y fragmentación espacial, transformando la morfología social urbana y suburbana. Vidal Koppmann (2002) describió que el sistema territorial quedó en una situación de desequilibrio en los aspectos físicos y sociales porque en las ciudades se generaron fragmentos separados de los núcleos tradicionales, los cuales quedaron encerrados dentro de fronteras que propiciaron la segregación social.

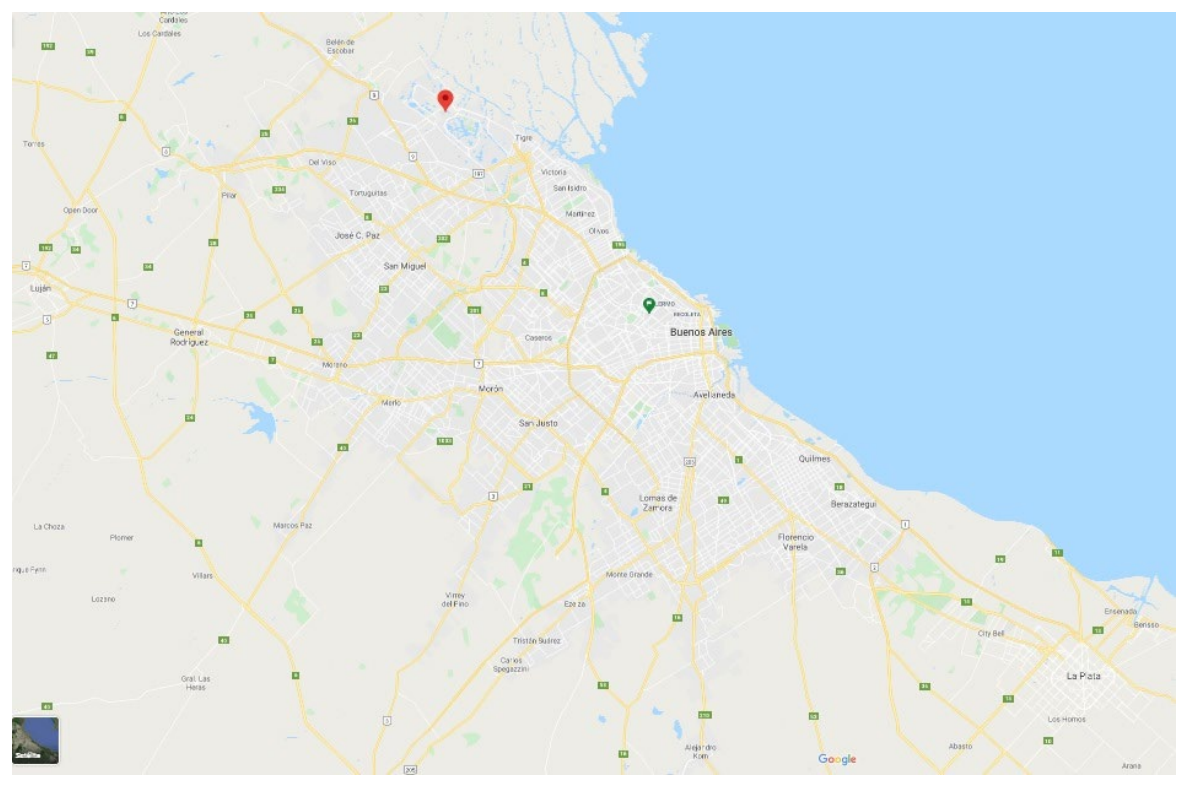

3) Ubicación de Nordelta dentro del AMBA.

Desde su fundación en el año 2000 se presentó con el lema «Nordelta: es vivir muy bien», como una idea del empresario Julián Astolfoni que se originó en 1972, con el antecedente de las construcciones estatales Villes Neuves de París y otros emprendimientos urbanísticos de Europa. Fueron 
presentados con la intención de atender una demanda insatisfecha, dado que en el Gran Buenos Aires no había urbanizaciones que pudieran ofrecer adecuadas infraestructuras de saneamiento y demás servicios, junto con una planificación urbanística racional, integrada y previsible en el futuro.

El proyecto fue aprobado en 1992 por la Provincia de Buenos Aires y en 1998 los empresarios Julián Astolfoni y Eduardo Costantini se asociaron para comenzar a hacer realidad la idea. 1999 fue el año de lanzamiento del primer barrio (La Alameda) y en el 2000 se entregó el primer lote para su construcción. Nordelta tuvo un desarrollo - regido por el plan director aprobado por Ley Provincial de Buenos Aires - con un alto grado de previsibilidad, y se convirtió, en palabras utilizadas en sus anuncios publicitarios, en la primera Ciudad Pueblo de la Argentina, rodeada de lagos, con más de 45.000 habitantes a la fecha ${ }^{4}$ (imagen 4$)$.

${ }^{4}$ Janoschka (2006) había caracterizado la construcción de Nordelta hasta 2006. El crecimiento constante permitió que hoy sea una Ciudad Pueblo consolidada con veintitrés barrios, 45.000 habitantes, cinco colegios, centro médico, centro comercial con más de setenta locales, cinco salas de cine, cuatro bancos, dos estaciones de servicio, veintitrés restaurantes (diez sobre una increíble bahía con amarras y salida al río Luján), un club deportivo y una cancha de golf de dieciocho hoyos diseñada por Jack Nicklaus, y un Hotel 5 estrellas. Para ver más: www.Nordelta.com (último acceso 25-03-2020). 


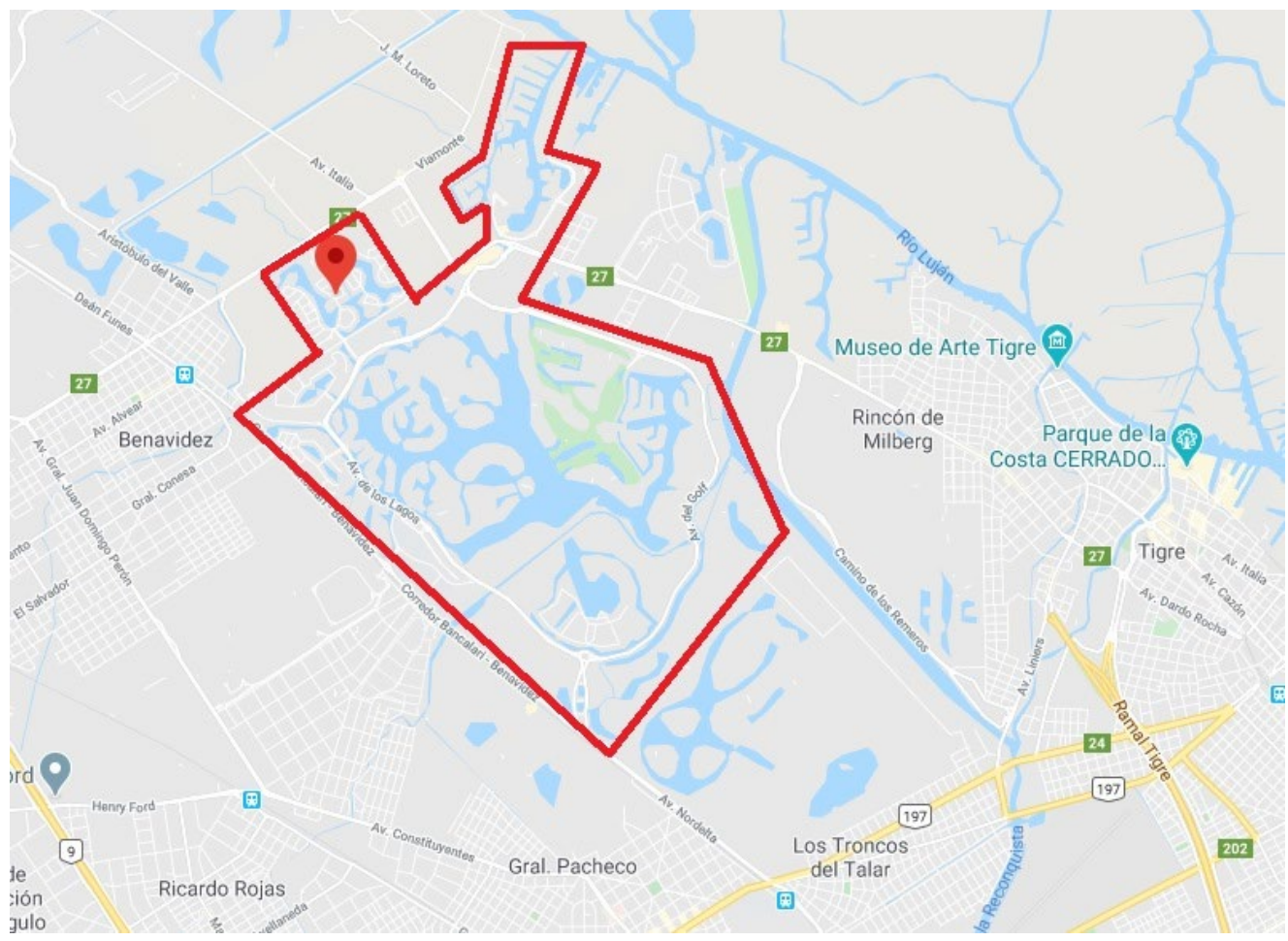

4) Nordelta demarcada en el mapa de Tigre.

Las transformaciones del espacio urbano han sido descritas en numerosos estudios temáticos (Svampa, 2001, Gorelik, 2011; Thuillier 2005; Vidal-Koppmann, 2001; entre otros), y hay documentos sobre los nuevos desarrollos de barrios cerrados en casi todas las metrópolis de Latinoamérica. Borsdorf (2002) reveló situaciones similares en Quito y Lima; Meyer y Bähr (2001) en Santiago de Chile; y Cabrales Barajas y Canosa Zamora (2002), así como Rodríguez Chumillas y Mollá Ruiz-Gómez (2002), estudiaron las transformaciones del espacio urbano en ciudades de México. Janoschka (2002), además de estudiar el caso de Nordelta, también analizó Alphaville en San Pablo, Brasil, como ejemplo de ciudades con la totalidad de servicios y funciones urbanas: trabajo, vivienda, recreación, consumo, cultura y educación.

Esta investigación se justifica porque aporta un análisis al incipiente campo de estudios sobre las experiencias juveniles en barrios cerrados de la Argentina - entendido como un ejemplo aplicable a otros modelos de ciudades latinoamericanas_-, prestando atención a la construcción de identidades, las 
trayectorias sociales, la vida en un barrio cerrado y la incidencia de la movilidad en prácticas socioculturales cotidianas.

\section{Metodología}

Se trabajó con una metodología cualitativa, por lo que se priorizó actuar sobre «contextos reales» y procurar acceder a estructuras de significados propias de esos contextos mediante la participación en los mismos (Vasilachis de Gialdino, 1993: 57). Se jerarquizó el criterio de la etnografía, es decir, la preocupación por captar el significado de las acciones y los sucesos para los propios actores. El sentido estuvo puesto en procurar la «fidelidad a la perspectiva de los actores involucrados en la realidad» (Sautu et al., 2005: 56). La actividad del trabajo de campo se desarrolló con una perspectiva etnográfica (Guber, 2001) y contó con la realización de notas de campo, entrevistas individuales, observación y encuestas.

El corpus de análisis estuvo constituido por el material discursivo producto de 84 encuestas virtuales y la observación y realización de entrevistas individuales en doce casos seleccionados de la población juvenil. El criterio de selección - construido sobre el acceso a los barrios que forman parte de Nordelta- priorizó diversidad de acuerdo al barrio de residencia, el género, prácticas sociales y culturales, y la diversidad presentada en las trayectorias sociales. El referente analítico se constituyó por los discursos obtenidos a partir de la desgrabación de las entrevistas, más los registros de campo y encuestas. También existió una recopilación documental sobre otros materiales relevantes, como fuentes estadísticas y periodísticas.

Las entrevistas permitieron la puesta en juego de una relación social donde se obtuvo información sobre la biografía, el sentido de los hechos, sentimientos, opiniones y emociones, y valores o conductas ideales de los informantes (Guber, 2001). La observación participante se utilizó como estrategia para acceder al campo, apoyada en un marco teórico general que guio la acción (Vessuri, 1992), y fundamentalmente con la puesta en juego del desarrollo de una cierta «sensibilidad» observacional en el acceso a jóvenes, con posibilidad de «clarificación de hallazgos» a través de controles con algunos de los miembros, por medio de la realización de entrevistas formales y de conversaciones informales, más el registro de notas organizadas y estructuradas (Kawulich, 2005). Para organizar el análisis de datos, se 
construyeron matrices de datos a partir de la revisión de las entrevistas (Marradi, Archenti y Piovani, 2010).

\section{RESULTADOS Y DISCUSIÓN}

Del estudio realizado se presenta un análisis dividido en dos secciones. En primer lugar, en «Trayectorias juveniles zigzagueantes con tintes estigmatizantes» se caracterizaron las trayectorias sociales de los jóvenes de Nordelta, su particular socialización y un tipo de estigmatización percibida en las cotidianeidades analizadas. Por otra parte, en «Días con alta movilidad, percepción de seguridad y rasgos de soledad» se analizó cómo era vivida la movilidad juvenil, principalmente en actividades educativas y deportivas, dando cuenta del funcionamiento de los barrios cerrados en vínculo con la sensación de seguridad, y una interpretación del tiempo en el que los jóvenes comparten o no con sus afectos.

\section{TRAYECTORIAS JUVENILES ZIGZAGUEANTES CON TINTES ESTIGMATIZANTES}

Una de las primeras cuestiones analizadas fue la autopercepción juvenil entre quienes formaron parte del estudio. El corpus de análisis presentó 84 testimonios de sujetos que establecieron estas cifras: el 89,3\% tenía entre 18 y 21 años, mientras que el 3,6\% tenía entre 13 y 16, otro 3,6\% entre 16 y 18 , y un $3,6 \%$ entre 25 y 30 años. Es decir, casi un $90 \%$ formaba parte de la franja etaria entre los 18 y 21 años, como dato importante para comprender sus trayectorias sociales y movilidad. Mientras que el $64,3 \%$ se los jóvenes residentes en Nordelta dijo ser argentino o argentina, un 32,1\% aseguró tener doble ciudadanía (argentina y europea), y solo un $3,6 \%$ era ciudadano latinoamericano.

Un dato importante para comprender las trayectorias familiares surge a partir de indagar sobre el lugar de nacimiento de los jóvenes estudiados. Solo el $14,3 \%$ de los jóvenes dijeron haber nacido en Nordelta. Una gran porción de la muestra $(64,3 \%)$ manifestó haber nacido en la zona norte del AMBA (principalmente San Isidro, Olivos y San Fernando), mientras que un 17,9\% admitió haber nacido en zona sur de la RMBA. Por otra parte, el 3,6\% - tal cual vimos con el dato sobre ciudadanía - nació en el exterior del país. 
Una de las cuestiones que aparecieron en las entrevistas tuvo que ver con conflictos familiares que despertaron las mudanzas a Nordelta, sobre todo en aquellas familias en las cuales los jóvenes se vieron apartados socialmente de su grupo de amigos del colegio y del barrio por decisión de los adultos, lo que ocasionó un conflicto de relación intergeneracional ${ }^{5}$. Nahuel (20 años) describió que durante los primeros seis meses en la casa nueva, prácticamente no estudió porque no se encontraba a gusto con el nuevo colegio secundario al cual tuvo que ir. Si bien con el tiempo se adaptó, el comienzo fue «durísimo». Algo similar describió Mily (23 años), quien argumentó una decisión familiar de mudarse de San Isidro a Nordelta con la que ella no estuvo de acuerdo. Una vez en el barrio nuevo, «negoció» con sus padres seguir estudiando en su colegio secundario habitual de San Isidro, y los adultos «lo tuvieron que aceptar». Sin embargo, eso implicó largos viajes que la tuvieron «muy cansada» casi dos años hasta terminar el colegio. Veremos en estas páginas cómo este primer conflicto intergeneracional planteado puertas adentro de los hogares se combinó con otras situaciones de conflictividad entre jóvenes y adultos, tanto al interior como al exterior de Nordelta.

Los trayectos educativos de los jóvenes estudiados mostraron una marcada presencia de colegios secundarios privados, principalmente Michael Ham, Northlands, Cardenal Pironio Marín y San Lucas; y universidades privadas - y en menor medida públicas - por fuera de Nordelta. Los jóvenes se referían a casas de estudio con aranceles elevados que se posicionaban como instituciones con una tradición muchas veces familiar. Se producía una elección educativa en una línea de continuidad entre familias y escuelas, que se justificaba en torno a un clima moral que era percibido como coherente, aunque no exento de diferencias (Fuentes, 2013 y 2015). Es decir, una tradición en la elección educativa donde familiares, amigos y conocidos iban heredando y contagiando formas de elección, que a veces se condensaban en alguna institución elegida por distintas generaciones.

De la muestra un $35,7 \%$ aún cursaba el secundario en colegios privados localizados dentro de Nordelta, mientras que un gran porcentaje $(64,3 \%)$ se encontraba desarrollando estudios universitarios, principalmente en las carreras de Derecho, Comercio, Economía, Ingeniería, Marketing y Periodismo, por fuera. Nordelta no tenía universidades propias, solo jardines y colegios

${ }^{5}$ El eje analítico de este artículo no se centra en la cuestión generacional (Mannheim, 1993), aunque sí ha sido desarrollado por el autor en otras ocasiones (Mutuverría, 2014, 2017 y 2020). 
primarios y secundarios. Se mencionaron algunos proyectos de extensiones de universidades privadas que aplicaron en zona, pero no prevalecieron. Esta situación representó un nuevo escenario de socialización para los jóvenes, que tuvieron que salir de Nordelta para poder acceder a sus estudios universitarios. Y no solo eso, también en algunos casos se eligieron casas de estudio muy diferentes a las que conocían.

Mateo (19 años) se había inscrito en UCES, en la sede más cercana, ubicada en el Shopping Remeros Plaza, en la localidad de Nuevo Delta, partido de Tigre. Contó que la decisión tuvo que ver con la cercanía y «el buen nombre» de la universidad, ya que había tenido buenas referencias entre amigos que ya cursaban ahí y «por la publicidad»en redes sociales y medios. En su experiencia, la cercanía y la recomendación de sus pares resultaron determinantes en la decisión de cursar sus estudios en esa universidad privada. Uno de sus amigos asistía a UCES sede Olivos, pero a él le resultaba muy lejos. La mayoría de los casos dijeron estudiar en la Universidad Di Tella, Universidad de Belgrano, Universidad de San Andrés y, en menor medida, Universidad de Palermo y Universidad de San Isidro.

Otros casos mostraron una variabilidad y un «desafío» en el tipo de universidad seleccionada, ya que pasaban a una institución pública. Inés (21 años) y Paolo (19 años) optaron por la Universidad de Buenos Aires (UBA). Si bien existía la posibilidad de cursar en la sede UBA del Centro Universitario Tigre (CUT) o en la sede de Martínez - mucho más cerca que la Ciudad Autónoma de Buenos Aires-, en ambos casos decidieron cursar en la sede central. Inés (21 años) comentó que quería realizar su carrera universitaria allí porque en lo académico era «la mejor del país». Se mostró un tanto sorprendida después de comenzar a cursar, porque se podía estudiar «sin pagar un arancel todos los meses». En la manera de describir su incorporación a la universidad pública, la joven describió que estar en la UBA era formar parte de un tipo de institución «más humanitaria», en el sentido de que era «súper masiva»y con «estudiantes diferentes», a partir de lo cual se podía aprender de la diferencia. Cursar en la UBA representaba sumar en «calidad humana».

Paolo (19 años) narró una tradición familiar mixta con universidades públicas y privadas. Tanto su padre como su hermana mayor estudiaron diferentes carreras en la UBA, mientras que su madre lo hizo en Di Tella. Su decisión reposó en parte en esa tradición - al elegir UBA-, y el argumento fue la profunda «calidad de docentes» y posicionamiento en «rankings internacionales». Él destacó que quería hacer una pasantía en el exterior 
posteriormente, así como el $68 \%$ de los jóvenes entrevistados. Solo un $4 \%$ había realizado una estadía en una facultad extranjera, mientras que un $28 \%$ dijo que no tenía deseos de viajar para estudiar.

Se analizó que en los relatos aparecían ejemplos de lo que Bourdieu (1988b) argumentó como «campo de los posibles», ya que estos jóvenes pudieron haber recibido un volumen determinado de «capital heredado». que posibilitó un «haz de trayectorias» más o menos probables que conducían a unas posiciones más o menos equivalentes (1988b: 108). Sin embargo, esto no les quitaba margen a las acciones de los propios sujetos juveniles, quienes en algunos casos actuaban y decidían itinerarios alejados de los mecanismos de reproducción intergeneracional vinculados a un tipo de educación universitaria localizada en determinadas casas de estudio (generalmente privadas y con «renombre») y con recorridos específicos conocidos familiarmente.

Machado Pais (2007) percibió a la acción juvenil enmarcada en un escenario de estructuras sociales cada vez más laberínticas, que podrían equipararse a «trayectorias yo-yo» donde, frente a estructuras sociales cada vez más fluidas y modeladas en función de los individuos y sus deseos, las juventudes sentían su vida marcada por crecientes inconstancias, fluctuaciones y discontinuidades; y donde sus pasiones eran como «vuelos de mariposa». El recurso a la metáfora del «yo-yo» ayudaba a expresar los movimientos oscilatorios y reversibles como si los jóvenes hiciesen de su vida «un cielo donde ejercitar su capacidad de aves migratorias», donde todo era dominado por «lo aleatorio» y todo parecía asentarse en una ética de la experimentación en tiempos zigzagueantes y veloces.

Esta conceptualización sobre las trayectorias juveniles zigzagueantes como sinónimo de la acción juvenil por fuera de trayectos heredadospermitió pensar distintas formas de ser y ocupar espacios - como algo no homogeneizante - y de distanciarse de las decisiones adultas. Se trataba de decisiones individuales en contextos habilitantes que representaban una posibilidad de acción por fuera de lo establecido en el barrio cerrado y en las decisiones familiares. Elegir estudiar en una universidad pública, por ejemplo, no respondía únicamente a una situación contextual - como que en Nordelta no existían universidades - , sino que era percibido como un autoagenciamiento juvenil que salía de los límites establecidos en las trayectorias familiares, y también permitía cruzar - por decisión del propio joven- el muro de las distancias físicas y sociales. Se trataba de una experiencia excitante que rompía 
con los mecanismos de reproducción intergeneracional, y también implicaba salir de la «burbuja» por un rato y vincularse con «lo desconocido».

Entre las relaciones sociales más destacadas por los entrevistados aparecieron grupos de amigos que se reunían habitualmente en casas o en el centro comercial, y en segundo lugar, la familia. Al charlar sobre la amistad, un $53,6 \%$ de la muestra argumentó que tenía un grupo «sólido» de entre cinco y diez amigos a quienes veía regularmente. Por otra parte, un 35,7\% dijo tener más de diez amigos regulares, y un 10,7\% admitió tener menos de cinco amigos. Los lazos de amistad se presentaron como opciones positivas de socialización que ocupaban gran parte del tiempo de ocio de estos jóvenes. Refiriéndonos a la composición familiar, un $81 \%$ de los jóvenes dijo tener papá y mamá y dos o más hermanos. Solo un $12 \%$ vivía con su mamá en familia monoparental, y un $7 \%$ con padres del mismo sexo. Lo que muestra una composición familiar diversa, aunque con predominancia de familias «tipo».

Entre las principales actividades de socialización juvenil apareció el deporte $(57,1 \%)$, seguido por actividades artísticas $(32,1 \%)$ y por quienes no realizaban ninguna actividad social $(10,7 \%)$. En la mayoría de los casos, el fútbol y el rugby solían ser los deportes favoritos.

Sergio (22 años) contó que jugaba al rugby como solían hacerlo su papá y sus primos. Cuando vivía en zona norte del AMBA perteneció al CASI (Club Atlético San Isidro), pero desde que se había mudado a Nordelta, practicaba en otros clubes cercanos, como el Club Pueyrredón, Club San Andrés y «el Newman» en Benavidez. En una de las entrevistas, dijo que al cambiarse notó que sus compañeros del club anterior se mostraron un poco distantes con él. $\mathrm{Y}$ sumó un recuerdo que sirvió para entender cómo se percibía ese cambio. En el grupo de whatsapp en el que organizaban un cumpleaños - que habitualmente implicaba juntarse en la casa del agasajado- le decían entre risas que «invitase al country», ya que "ahora tenía más plata».

Por su parte, Theo (20) practicó fútbol desde muy chico y en el momento de la entrevista se mostró muy contento de jugar en el Club Nordelta, como parte de una liga en la que participaban equipos referentes de la zona norte, desde Canning hasta San Isidro. En su relato tomó forma una temática que, según argumentaba, aquejaba a muchos de los jóvenes de la zona. Theo dijo que había «una suerte de prejuicio» en no simpatizar con las personas con «más privilegios económicos». Era algo que notaba en general, cuando se referían a quienes vivían en Nordelta, pero que en el fútbol tenía otra resonancia 
porque «el odio se multiplicaba por 10», donde había «cero respeto», y jugar de visitante en los diferentes partidos de la liga implicaba numerosos insultos de la gente que estaba en la tribuna. Entre las frases estaban: «Chetos de mierda», «pendejos acomodados», «pendejos mantenidos». Inclusive le llamaba la atención que les decían «córtense el pelo» de manera despectiva. Esta situación, muchas veces naturalizada en distintos deportes, pero principalmente en el fútbol en Argentina, excedía la relación jugadores-hinchada, y también entraba a la cancha. Este joven relató que, si eventualmente se quejaban de alguna maniobra del árbitro, recibían respuestas del estilo: «Decile a tu viejo que venga a defenderte».

Los distintos relatos sobre el etiquetamiento de los miembros del equipo por vivir en Nordelta se extendían en el tiempo, y tanto Theo como otros jóvenes aseguraron que se hacía «costumbre» porque estaban «destinados»a que los «puteen desde el vamos y en mil idiomas». Esta naturalización de la mirada externa mostraba un recurso interno para sobrellevarlo. Contaron que los comentarios entre ellos después de los partidos siempre tenían que ver con qué nuevas puteadas o frases aparecían como «originales» y compartían esas nuevas etiquetas.

Sin embargo, también emergían algunas consideraciones reflexivas sobre cómo ellos mismos presentaban estas escenas como algo «normal» y que «nadie ni siquiera lo cuestiona». De hecho, Theo contó que cuando recién arrancaba, a los 15 años, le había impactado mucho cómo un padre de un jugador rival lo puteaba por ser de Nordelta y su propio hijo lo miraba con vergüenza. Para él, esto fue decisivo para comprender cómo en el fútbol en general, pero también en condiciones de amateurismo, estaba «todo podrido».

Esto resultó inquietante para seguir indagando, sobre todo por la particularidad de representar tanto una disputa juvenil (entre jóvenes varones futboleros de diferentes estratos sociales) como un conflicto intergeneracional (entre jóvenes y adultos que les atribuían una carga de desconfianza y recelo). Esto coincide, en parte, con los estudios de Alvarado, Rodríguez y Vommmaro (2013) y Vommaro (2016), en los que se analizaron las políticas públicas en torno a las juventudes latinoamericanas, visualizando un escenario cargado de un conjunto complejo y preocupante de paradojas vinculadas a la persistencia de mecanismos de reproducción intergeneracional de las desigualdades.

El rugby y el fútbol también han sido estudiados en Argentina como ámbitos de producción de una juventud moralizada y positivizada (Fuentes, 
2019). Mientras que en el rugby aparecía una elite con valores que portaba una distinción, en un juego de contraposición, el popular fútbol no solo se asociaba a otra condición y pertenencia de clase, sino que también era visto, desde las elites, como una práctica en la que los jóvenes perdían «el norte» (Fuentes y Guinness, 2018).

En la juventud estudiada, el ejemplo del deporte - como práctica de socialización - mostró cómo los etiquetamientos afectaban las trayectorias juveniles y daban cuenta de un tipo de percepción que se naturalizaba entre los propios integrantes de los equipos deportivos. En las diferentes entrevistas, charlas informales y encuesta, cuando se presentaba la temática discriminación en primera persona, solo un $17,9 \%$ dijo haberse sentido discriminado. Por su parte, un 21,4\% aseguró que «tal vez» se había sentido afectado de ese modo, y un $60,7 \%$ señaló que no había sido discriminado. Mientras que — al poner el foco en casos externos e indagar si conocían ejemplos de amigos o familiares discriminados - un 69\% confirmaba que conocía personas de su entorno que lo habían sufrido en carne propia, y solo un 31\% decía que no era así. Lo cual indicaba, de manera indirecta, una cercanía con la temática del etiquetamiento externo que se vio con el ejemplo del deporte. Indagando un poco más, al preguntar: "¿Alguna vez sentiste que la gente te veía diferente cuando se enteraba de que vivías en Nordelta?», el 64,3\% de los jóvenes respondió afirmativamente, y solo un $35,7 \%$ optó por una respuesta negativa.

Entre los relatos de quienes se sintieron discriminados por vivir en el barrio cerrado, apareció la voz de Nicolás (23 años), quien contó que al conocer a personas en las redes sociales, siempre indagaban mucho más sobre su vida cuando decía que vivía en Nordelta, y le preguntaban cuestiones sobre el funcionamiento del barrio, y más de una vez le habían escrito: «Ah, si vivís en Nordelta, entonces sos un cheto de mierda». Su testimonio fue un poco angustiante porque él sentía que quienes no lo conocían pensaban que tenía su vida «resuelta» económicamente y en la práctica eso no solo no era así, sino que sus padres enfatizaban en que gestionase su propio dinero. En este sentido, el manejo de la financiación fue un tema indagado, y solo el 18\% dijo utilizar dinero generado por su trabajo, mientras que el $82 \%$ recibía aportes de sus padres.

Macarena (19 años) contó algo que le preocupaba en el marco de su participación dentro de la universidad. Se refirió a que en una de las clases tuvieron que leer unos textos de autores que hablaban sobre barrios cerrados y muchos de sus compañeros empezaron a opinar sobre «los chicos de Nordelta» 
como algo «estático» y con «bastante desdén», hasta que ella decidió tomar la palabra y decir que vivía allí, y que pensaba que no todos eran iguales, y la situación cambió. Desde ese momento, ella tomó conciencia de que «mucha gente» pensaba que vivir en Nordelta era, de por sí, «algo malo».

La categoría de estigma de Goffman (2010) resulta útil para el análisis. El autor lo define como un atributo que produce un descrédito amplio y constituye una divergencia entre la identidad social virtual y la real, produciendo un aislamiento entre la sociedad y la persona. Independientemente de los tres tipos definidos por el autor ${ }^{6}$, la clasificación del estigma está estrechamente vinculada a cada situación que viva un sujeto por el solo hecho de ser denigrado. En la línea de los trabajos de Goffman (2006; 2010), existen numerosos estudios que analizaron el estigma desde las situaciones conflictivas, enemistades, peleas, así como su importancia en las relaciones de interacción entre jóvenes (Tomasini, Domínguez y Peralta, 2014), las humillaciones (Kaplan, 2009), las creencias estereotipadas con respecto a las diferencias de género, la naturalización de la violencia y la diversidad sexual y la xenofobia (Díaz Ledesma, 2011), y en torno a procesos de discriminación y estigmatización de jóvenes homosexuales en sus escuelas (Molina y Maldonado, 2011), entre otros.

Resultó pertinente pensar que el tipo de discriminación argumentada por estos jóvenes delineaba una manera en la que otros jóvenes (y también adultos) los estigmatizaban constantemente. Un significado que los homogeneizaba, de acuerdo a los discursos analizados, y planteaba que los jóvenes de Nordelta eran «chetos», «pendejos mantenidos», que vivían en un lugar «malo», motivo de «burla», seguramente «adinerados», que se encontraban «destinados» a que los «puteen desde el vamos y en mil idiomas» al salir del barrio cerrado. Y estas estigmatizaciones se mostraron también en el relevo, ya que independientemente de la discriminación por pertenencia a Nordelta - también hubo otros temas que emergieron en la encuesta y durante las entrevistas. En cifras, los motivos de discriminación percibidos tuvieron que ver principalmente con: la contextura física $(32,6 \%)$, ser considerado adinerado $(21,4 \%)$, orientación sexual $(13,7 \%)$, costumbres $(10,7 \%)$, color de piel $(8,8 \%)$ y nacionalidad $(5,6 \%)$.

${ }^{6}$ Goffman (2010) plantea tres tipos de estigmas: en primer lugar, las deformaciones físicas; por otro lado, defectos del individuo como falta de voluntad, creencias, deshonestidad; y por último, estigmas de raza, religión y nación. 
Las interacciones con etiquetamientos, discriminación, desvalorización y/o acusación eran vividas como algo angustiante entre los jóvenes estudiados. Cada uno presentaba modos distintos de sobrellevar esas situaciones. Por un lado, había una naturalización — sobre todo en la socialización deportiva - por la cual se aceptaba esa mirada externa y se optaba por el silencio, entendiendo la situación como algo imposible de cambiar. Por otra parte, había una manera de explicitar la pertenencia a Nordelta - como en el caso de la estudiante en la clase universitaria - que, al tomar la palabra, argumentaba una situación, tensionaba prejuicios y descomprimía miradas estigmatizantes.

\section{DíAS CON ALTA MOVILIDAD, PERCEPCIÓN DE SEGURIDAD Y RASGOS DE SOLEDAD}

La juventud residente en Nordelta desplegaba una alta movilidad propia en hacer cotidiano. La circulación por la localidad y sus barrios, y por fuera es decir, en Tigre, Pacheco y zonas aledañas de la zona norte del AMBAmostraba una alta autonomía juvenil, aunque presentaba algunos matices. Al indagar sobre cómo era el tipo de traslados que se realizaban para salir del barrio cerrado, el $68 \%$ de los jóvenes estudiados decía que se manejaba en su propio automóvil. Los otros modos de viajar eran a través de aplicaciones como Uber o Cabify (14\%), conduciendo el auto familiar (10\%) y en bicicleta (8\%). Aquí es preciso indicar que los principales lugares transitados tuvieron que ver con instituciones educativas y deportivas, visitas a familiares y amigos (un $78 \%$ identificó que vivía fuera de Nordelta, aunque en zona norte), o actividades de ocio vinculadas con la Ciudad Autónoma de Buenos Aires (vivida como una excepción). En estos diversos escenarios traspasar los muros de Nordelta implicaba conducir en automóvil decenas de kilómetros.

Nancy (20) contó que el trayecto desde su casa —en uno de los barrios de Nordelta - hasta su facultad en Olivos le demandaba un viaje de alrededor de 23 kilómetros, y una media hora en el auto como mejor opción. Otra alternativa implicaba recorrer por Ramal Tigre, pero tardaba más. De todos modos, la joven aseguró que si el recorrido era «en hora pico», podía ser «un desquicio» el tránsito. Por su parte, Octavio (27) contó que concurrir a su práctica de rugby en San Isidro también implicaba un traslado significativo. En auto propio eran más de 21 kilómetros, y más de 30 minutos de demora en el mejor de los casos. Mientras que una ruta alternativa en vehículo eran más de 
$24 \mathrm{~km}$ en casi una hora de viaje, y si elegía viajar en tren (opción no seleccionada entre los jóvenes), más de dos horas (imágenes 5 y 6 ).

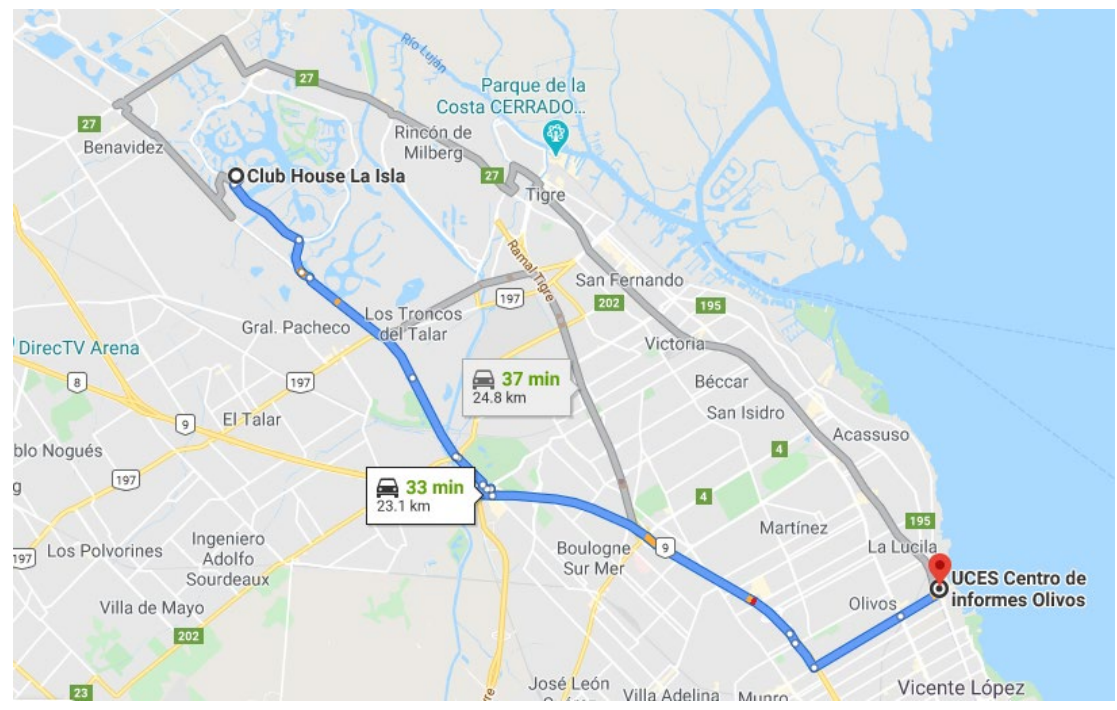

5) Traslado de Nancy del barrio La Isla de Nordelta a Olivos.

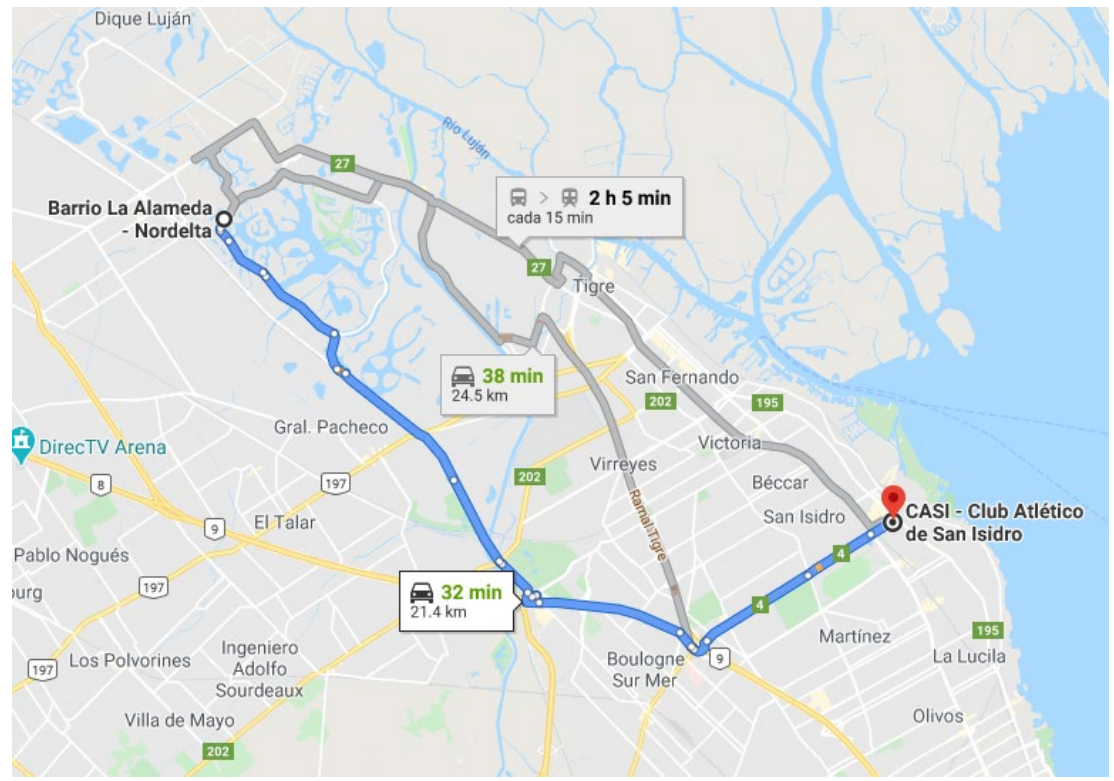

6) Traslado de Octavio del barrio La Alameda de Nordelta al CASI de San Isidro. 
Luciana (15) se mostró muy entusiasmada por las salidas que eventualmente hacían con amigas a la Ciudad Autónoma de Buenos Aires, aunque aclaró que eran «muy de vez en cuando» porque la capital «era un caos». En esta reiterada frase entre los jóvenes, la ciudad capital aparecía como la otredad a la imagen de tranquilidad y naturaleza que representaba el lugar donde vivían. Esto coincide con lo categorizado por Svampa (2002) como «ruralidad id́lica», es decir, como un conjunto de valores entre los cuales la pertenencia a una sociedad armoniosa y ordenada se combinaba con principios ecológicos y con cierta filosofía hedonista y desestructurada. En ese reconocimiento y autopercepción del lugar en el que vivían como algo «súper tranquilo», las salidas se tornaban muy planificadas, raramente ocasionales y siempre pensadas como ocasiones especiales, de las que potencialmente se podía «escapar» para regresar a la tranquilidad del barrio cerrado. En este sentido, viajar a Capital, según la joven, significaba una experiencia excitante vivida como posibilidad para alejarse del orden establecido como planificación rígida de todos los días, algo así como "salir de la burbuja». Un ejemplo que comentó fue una salida al teatro que habían hecho recientemente y había representado un viaje de casi $42 \mathrm{~km}$ en 50 minutos, más la espera para conseguir estacionamiento en el centro de la ciudad y la demora por peajes en los accesos a CABA (imagen 7).

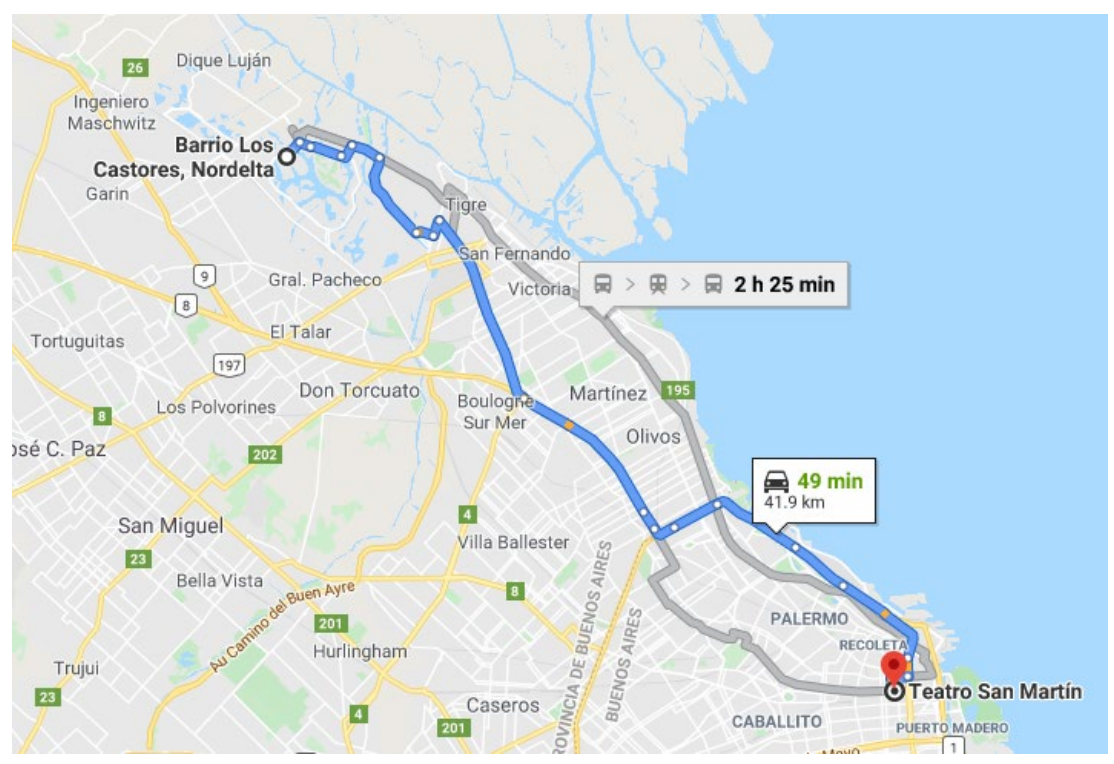

7) Traslado de Luciana desde Castores (Nordelta) hasta la Ciudad Autónoma de Buenos Aires. 
Otra cuestión que resultó importante en el análisis tuvo que ver con el discurso por una única salida diaria de Nordelta. Los jóvenes aseguraban que si iban a la facultad y querían visitar amigos fuera del barrio cerrado. unían ambas actividades para no viajar tanto. Lo mismo si practicaban un deporte y tenían que cursar sus estudios posteriormente. También las salidas de los fines de semana representaron un tema en la gestión de traslados. Mateo (19) aseguró que cuando salía con sus amigos a Pilar, generalmente prescindían de sus automóviles y se quedaban a dormir en la casa del amigo «más cercano a la zona». Por su parte, Macarena (19), por lo general, salía media hora antes del horario habitual todas las mañanas porque si no, el ingreso a los colegios significaba un «colapso de autos» en el barrio, ya que todos los padres llevaban a sus hijos en auto. Después pasaba su jornada de estudios y unía «eso con algo más», para luego volver a su casa y «no salir más». Con esto, aparecía otra cuestión valiosa que contrastaba la sensación de una alta movilidad asociada al placer y la libertad de acción: el viaje «único» como alternativa a la distancia. Es decir, planificar la cotidianeidad sobre la base de - en el mejor de los casos - una sola salida diaria de Nordelta, y — en lo posible - en horarios que favoreciesen el «poco tránsito», lo cual demandaba una planificación muy estricta.

En otro sentido, la circulación dentro de los barrios y las cifras de movilidad de los jóvenes presentaban una leve variación respecto de cómo se percibía un viaje al exterior del barrio cerrado. Adentro del barrio, el 68\% utilizaba su propio vehículo para trasladarse, un $18 \%$ caminaba y un $14 \%$ utilizaba su bicicleta o rollers por las calmas calles. En esta circulación interna se percibía la vista de la naturaleza como algo positivo, al igual que vivir con acceso a los lagos o espacios comunes. La proximidad a los muros se veía como un elemento desvalorizante en la sensación de bienestar cotidiano.

Nordelta era presentado y ofrecido en la prensa -antes de su construcción - como un «retorno» a las comunidades igualitarias y civilizadas, con una organización interna, donde cada propietario era ante todo un «accionista» o «socio» ${ }^{7}$. En ese sentido, las lógicas internas del barrio en la mirada juvenil aparecían con una conflictividad particular. Entre las principales situaciones de conflictos entre vecinos se enumeraron: mal estacionamiento

${ }^{7}$ Las fuentes periodísticas utilizadas incluyeron suplementos de los diarios más importantes de Argentina (Clarín y La Nación) dedicadas exclusivamente a countries, así como notas publicadas en distintas secciones informativas del diario en papel y las plataformas informativas web, por fuera de esos suplementos. 
(42\%), ruidos molestos $(24 \%)$, problemas con las mascotas $(18 \%)$, utilización errónea de los espacios comunes (11\%) y discusiones «innecesarias» en el foro de vecinos $(7 \%)$. Esto último estaba sujeto a un tipo de organización particular al interior de los barrios, donde cada uno de ellos funcionaba como sociedades anónimas, que compartían acciones entre Nordelta S.A. y los vecinos.

La zona de conflictividad mencionada podía tener importantes efectos sociales dentro de cada barrio. Por un lado, si se trataba de desconocidos o de personas cuyos valores morales no se ajustaban a los exigidos, su petición de ingreso o su permanencia podía ser rechazada por una comisión disciplinar. Lo mismo ocurría para vecinos recién llegados que se ajustaban a los reglamentos establecidos por el tribunal de disciplina, con posibilidad de recibir observaciones, intimaciones o multas. Por otra parte, el desenvolvimiento armonioso y estrictamente controlado dentro del barrio les otorgaba valor a los rumores, aunque de una manera menos institucionalizada, y las acusaciones en la cartelera de anuncios de la guardia de cada barrio, el club house o el foro de vecinos eran formas de visibilización de conflictos que servían para controlar y reprimir los desvíos ocasionales dentro de los barrios. Según los relatos, el principal motivo de conflictos era el incumplimiento del pago de expensas y las multas por exceso de velocidad, ambas cuestiones que se publicaban con listados impresos con identificación de quienes formaban parte de los incumplimientos en el acceso de cada barrio. Esos conflictos internos representaban una amenaza al cumplimiento de los buenos valores y costumbres entre los vecinos, y también podían ocasionar un motivo de «ostracismo social» (Lacarrieu y Thuillier, 2001), es decir, una pérdida del contacto social ocasionada por la marginación entre los miembros de la comunidad.

Sumado a la cuestión de la naturaleza y tranquilidad, los jóvenes también asociaban a Nordelta con la sensación de vivir en seguridad. En cifras, un 44\% dijo sentirse «muy seguro», un 38\% «seguro», un 18\% «poco seguro»y nadie optó por la opción de barrio «inseguro». En el desglose de casos y experiencias, un $22 \%$ había vivido algún «episodio de inseguridad», un $8 \%$ admitió que «quizás», mientras que un $72 \%$ aseguraba que no. Esas aseveraciones se combinaban con una percepción del presente como escenario de preocupación. Un $24 \%$ aseguraba vivir «con preocupación» sobre su seguridad o la de su familia, un $40 \%$ se mostraba «poco preocupado» y un $34 \%$ de los entrevistados decía sentirse «nada preocupado». 
Profundizando en el uso del territorio y el tiempo de ocio, los jóvenes se refirieron a las salidas con amigos y la familia en Nordelta, por lo general, al centro comercial o «la bahía». Un 47\% salía al menos tres veces por semana entre amigos, mientras que un 53\% lo hacía dos o tres veces. En familia, el 50\% admitió salir al menos una vez por semana, el $30 \%$ dos o tres veces, y un $20 \%$, ninguna vez. La configuración espacial de los barrios de Nordelta, la proximidad de infraestructura vial y de comunicación, la disponibilidad de servicios urbanos y los imaginarios acerca de los residentes de cada uno de esos espacios establecían, en términos de Bourdieu (2002), una distancia «socialmente producida» entre diferentes lugares y actores. Las posiciones y distancias sociales dentro de la ciudad marcan recorridos que delimitan un núcleo aglutinador. En este caso, el centro comercial y la bahía grande se identificaban como espacios compartidos, y también como sinónimos de un centro que unificaba y era rodeado por barrios residenciales que eran sus anillos circulares. Aquí hay un punto de coincidencia con el análisis por la «moda» que describió Janoschka (2006) en la privatización de las ciudades latinoamericanas.

De todos modos, existían estrategias juveniles que escapaban de estas dinámicas descritas. Luciana (15) solía ir con su papá a hacer compras a Benavidez, una zona aledaña que quedaba por fuera del circuito comercial de Nordelta. La joven explicaba que en casi la misma distancia física, encontraban «mejores precios» en productos de «buena calidad» que vendían locales «más chicos», donde había un trato «más cercano» y cordial. Esto se percibió como una estrategia, en términos económicos y sociales, de poder escapar a la lógica de consumo que imponía el centro comercial, como anillo circular de los barrios cerrados de Nordelta.

Indagando sobre la utilización del tiempo diurno en soledad, un $25 \%$ de los jóvenes admitió pasar entre 8 y 10 horas solos en sus casas, un 45\% entre tres y cinco horas, y un 30\% menos de tres horas al día. Al referirse al tiempo que consumían sus actividades por fuera de sus hogares, un 66\% admitió que estaba fuera de su casa entre siete y diez horas reloj al día, un $24 \%$ entre cinco y seis horas, y un $10 \%$ entre tres y cuatro horas.. Como ejemplo, Nancy (20) contó que sus días solían ser «bastante solitarios», porque sus padres trabajaban todo el tiempo. Su papá en la semana alquilaba un departamento en Recoleta (Ciudad Autónoma de Buenos Aires) porque su trabajo lo «demandaba mucho» y solo lo veía los fines de semana, cuando iba a la casa de Nordelta. Su mamá salía muy temprano y volvía a media tarde, con lo cual se cruzaban solo dos 
tardes a la semana, y también compartían más tiempo el fin de semana, siempre y cuando la mamá no tuviese salidas con sus amigas. Sus horarios la mantenían más de seis horas fuera del hogar, y la dinámica laboral de sus progenitores les quitaba espacio para compartir tiempo. Eso mostraba a la joven un poco apenada, aunque argumentaba que lo entendía porque «sus carreras» lo demandaban.

Esto último representaba dos cuestiones que sumamos al análisis: por un lado, reafirmaba la capacidad de movilidad propia de los jóvenes al interior del barrio cerrado - principalmente en planes con amistades - sin depender de la movilidad familiar. Esto sumado a la movilidad fuera del barrio, que también era alta. Por otra parte, marcaba una socialización familiar particular, donde escaseaba - a simple vista - el tiempo compartido con padres, hermanos o familiares (inclusive las visitas), y mostraba que los jóvenes pasaban muchas horas al día solos. Sin embargo, contrariamente a ser planteado como un motivo de conflicto intergeneracional, esa soledad juvenil era percibida como un rasgo «necesario» por la «demanda laboral» de los adultos en vínculo con el sostenimiento económico de un tipo de vida armoniosa y vinculada con la naturaleza, aunque con elevados impuestos y costos mensuales. En otras palabras, los jóvenes entendían esa soledad como parte del "sacrificio» que había que hacer para sostener económicamente el poder vivir en un barrio cerrado.

Con lo dicho, la dinámica diaria en Nordelta mostraba a sus jóvenes residentes con salidas diarias para estudiar, trabajar o practicar deporte - en muchos casos con la sumatoria de otra actividad extra para amortizar el viajey un regreso a la casa por la noche. Es decir, las grandes distancias y el tiempo que demoraba el viaje requerían una planificación previa y detallada. El acceso a una movilidad propia permitía que tuviesen un desplazamiento autónomo por la localidad y otros territorios de zona norte o CABA.

Por último, aparecía un rasgo importante en el vínculo que estos jóvenes presentaban con las problemáticas sociales. Entre los intereses manifestados, en primer lugar estaba la cuestión de la pobreza y desigualdad social $(42,9 \%)$, seguido por el medioambiente $(28,6 \%)$, la política $(14,3 \%)$ y la corrupción $(14,3 \%)$. En este sentido, un $42,9 \%$ de los entrevistados participaba de «actividades solidarias», mientras un $57,1 \%$ no lo hacía. Esto último representó un nuevo interés para indagar la acción juvenil en Nordelta. 


\section{CONCLUSIONES}

Se puede concluir destacando algunos aspectos y formas de ser jóvenes en los barrios cerrados de Nordelta. La constitución de identidades a partir del discurso colocaba la percepción juvenil de vivir en un barrio cerrado paradigmático en la zona norte del AMBA y en Argentina - como un escenario con ventajas y desventajas.

En primer lugar, los jóvenes mostraron diferencias en sus percepciones sobre la vida en el lugar y las formas de seguir o no itinerarios que respondían a tradiciones familiares o lógicas de acción establecidas en el lugar, lo cual representó un ejemplo de heterogeneidad que aporta a los estudios juveniles alejados de una idea homogeneizante sobre esa porción de la sociedad. Por medio de este estudio se muestran disposiciones subjetivas diferenciadas que daban cuenta de una acción juvenil particular.

Los barrios de residencia aparecieron como ámbitos privados vinculados a la sensación de bienestar y seguridad, con proximidad a la naturaleza y percibidos como refugios en la cotidianeidad: eran lugares a los que se volvía escapando de la urbanidad y su caos para estar en tranquilidad. Existía una alta movilidad para poder manejarse en las distancias que implicaban el barrio en conexión con otros de la localidad, y también en las conexiones con el exterior (instituciones educativas, deportivas y culturales), lo que daba cuenta de una experiencia diaria con capacidad de gestión de rutinas con solvencia económica. Se trataba de condiciones de vida que presentaban la opción de residir en un barrio con servicios básicos asegurados, más la presencia de parques, instalaciones deportivas, áreas comunes de la vida social, instalaciones para eventos sociales, etc.

Esto constituía una sensación asociada al privilegio que excedía el factor económico y marcaba una pertenencia establecida, sobre todo, por vínculos familiares y entre amistades. Aunque también presentaba el desafío de la aceptación y convivencia entre vecinos en un ámbito con alta regulación, normas de convivencia y penalidades aplicables, con el riesgo de caer en el ostracismo social de no cumplir con lo establecido.

En los discursos juveniles aparecía un balance ambivalente respecto de la residencia en el lugar. Mientras la tranquilidad de la naturaleza y el hogar en un ámbito seguro cumplía con la expectativa en la mayoría de los casos siendo conscientes de que eran producto de decisiones tomadas por adultos al 
momento de mudarse a Nordelta—, esa vida natural en la «ciudad pueblo» traía aparejada un contraste, traducido en una limitada interacción social dentro del barrio, debido a que muchos amigos y familiares vivían lejos y no se visitaban frecuentemente, sumado a que los vecinos no se visitaban habitualmente.

Por otra parte, las trayectorias juveniles daban cuenta de la presencia de tintes de estigmatización, debido a que las miradas exteriores etiquetaban a los jóvenes principalmente por el lugar donde vivían, y eso era percibido con atributos negativos: vivir en Nordelta como algo malo y viciado de privilegios económicos. Esto era advertido con naturalización y angustia, a tal punto que en algunos casos los jóvenes se sentían destinados al desprecio. Sin embargo, la contracara indicaba que una porción de la población juvenil contrarrestaba el efecto del prejuicio con argumentos en situaciones donde se enfrentaba a la gente que estigmatizaba, sean jóvenes o adultos, y eso descomprimía los malos momentos.

La lejanía que representaba ir a la universidad, al club de deportes o a otra localidad de zona norte o a la Ciudad Autónoma de Buenos Aires mostraba una planificación selectiva sobre las rutinas juveniles. A pesar de tener libertad de acción y traslados en automóviles propios o familiares, el esfuerzo por planificar el tiempo y limitar los viajes excesivos insumía mucha energía en el día a día y era presentado como un factor negativo. Las ocupaciones mantenían a estos jóvenes y sus familias gran parte del día afuera de sus casas, dando cuenta de muchas horas de soledad, y — como paradoja - del poco disfrute del barrio, su naturaleza y tranquilidad.

El análisis propuesto también permitió la visibilización de conflictos intergeneracionales con algunos ejemplos situados en el orden de lo intrafamiliar (como las disputas por la decisión de vivir en Nordelta o la ruptura con tradiciones educativas familiares) y con presencia de fricciones entre jóvenes y adultos por fuera de la familia (como el recelo y desprecio sufrido por los jóvenes en los ámbitos de socialización deportiva).

Por último, existían estrategias para escapar de la burbuja que resultaban vitales en los relatos, como ser las salidas esporádicas a CABA, percibir la elección de estudios en universidades públicas como nuevas opciones de enriquecimiento personal y evadir las zonas comerciales consagradas como centros comerciales del barrio, para visitar almacenes en barrios periféricos. Estos ejemplos se interpretaron como pequeños logros que rompían con la lógica de funcionamiento de consumos en el barrio cerrado, y que paliaba el 
aislamiento territorial, la ausencia familiar gran parte del día y la soledad reiterada.

RECIBIDO: 15 DE MAYO DE 2020

ACEPTADO: 11 DE JUNIO DE 2020

\section{BibLIOGRAFÍA}

Alvarado, S. V., Rodríguez, E. y Vommaro, P. (2013). Políticas públicas de juventud e inclusión social en América Latina y el Caribe. Buenos Aires: UNESCO, CLACSO.

Beltrán, G. y Heredia, M. (2002). La emergencia de los barrios privados en Buenos Aires. Algunas reflexiones sobre la distribución del espacio a partir de Simmel y Elías. Apuntes de Investigación del CECYP, (8).

Borsdorf, A. e Hidalgo, R. (2004). Formas tempranas de exclusión residencial y el modelo de la ciudad cerrada en América Latina. El caso de Santiago. Norte Grande, 32, 21-37.

Bourdieu, P. (1988a). La distinción. Criterios y bases sociales del gusto. Madrid: Taurus.

. (1988b). Cosas dichas. Buenos Aires: Gedisa S. A.

Bourdieu, P. y PASSERON, J. C. (1977). Reproduction in education, society and culture. Beverly Hills, CA: Sage.

BRISCIOLI, B. (2009). Reconstrucción de las Trayectorias Escolares de Alumnos de Escuela Media en situación de vulnerabilidad. Reflexiones en torno a la categoría Trayectorias Escolares. En III Congreso Internacional de Educación, Universidad Nacional del Litoral, Santa Fe, Argentina.

ButLer, J. (1993). Bodies that matter. London: Routledge.

CABrales BARAJAs, L. y CANOSA ZAMORA, E. (2002). Nuevas formas y viejos valores: urbanizaciones cerradas de lujo en Guadalajara. En L. F. CABRAlES (Ed.), Latinoamérica: países abiertos, ciudades cerradas (pp. 93-117). Guadalajara: Universidad de Guadalajara-UNESCO.

Chaves, M. (2005). Juventud negada y negativizada: representaciones y formaciones discursivas vigentes en la Argentina contemporánea. Última Década, 13(23), 9-32.

. (2010). Jóvenes, territorios y complicidades. Una antropología de la juventud urbana. Buenos Aires: Espacio Editorial. 
Choudrie, J. y DwIVEDI, Y. K. (2005). Investigating the research approaches for examining technology adoption issues. Journal of Research Practice, 1(1), 112.

Ciccolella, P. (2011). Metrópolis latinoamericanas. Más allá de la globalización. Quito: OLACCHI.

DÁvila, O. y GHiARdo, F. (2005). Trayectorias, transiciones y condiciones juveniles en Chile. Nueva Sociedad, 200, 114-126.

DÁvila, O., Ghiardo, F. y Medrano, C. (2005). Los desheredados: Trayectorias de vida y nuevas condiciones juveniles. Santiago de Chile: CIDPA.

DerridA, J. (1981). Positions. Chicago: University of Chicago Press.

Dombois, R. (1998). Trayectorias laborales en la perspectiva comparativa de obreros en la industria colombiana y la industria alemana. En L. ZAmudio, T. Lulle y P. VARGAS (Coords.), Los usos de la historia de vida en las ciencias sociales (pp. 171-212). Anthropos.

Dukuen, J. y Kriger, M. (2016). Solidaridad, esquemas morales y disposiciones políticas en jóvenes de clases altas: hallazgos de una investigación en una escuela del conurbano bonaerense (2014-2015). Astrolabio, (16), 311-339.

FREYTES Frey, A. (2009). En los bordes del trabajo: los sentidos subjetivos del trabajo para jóvenes varones y mujeres con inserción laboral precaria. En $9^{\circ}$ Congreso Nacional de Estudios del Trabajo.

Fuentes, S. (2015). La formación moral de los jóvenes de elite en circuitos de educación privada en Buenos Aires. Pro-posiçoes, 26(2), 75-98.

. (2019). Juventud positivizada en Buenos Aires: clase, moral y estética en la producción de juventudes contemporáneas. Última Década, 27(51), 123-159.

FuENTES, S. y GuINNESS, D. (2018). Nacionalismos deportivos con «clase»: el rugby argentino en la era profesional/global. Antípoda. Revista de Antropología y Arqueología, 30, 85-105.

GOFFMAN, E. (2006). La presentación de la persona en la vida cotidiana. Buenos Aires: Amorrortu Editores.

. (2010). Estigma, la identidad deteriorada. Buenos Aires: Amorrortu Editores.

GoreliK, A. (2011). Correspondencias. Arquitectura, ciudad, cultura. Buenos Aires: SCA/Nobuko.

GuBER, R. (2001). La etnografia: método, campo y reflexividad (Vol. 11). Barcelona: Norma. 
HALl, S. y Du GAY, P. (Eds.) (1996). Questions of Cultural Identity. London: SAGE Publications.

HeRnÁNDEZ, F. M. (2009). Urbanizaciones privadas en América Latina, los «guetos» del Siglo XXI. El caso del crecimiento de countries y barrios privados en la costa atlántica argentina. Ponencia presentada en el EGAL. Caminando en una América Latina en Transformación, 3-7 de abril.

JACINTO, C. (2010). La construcción social de las trayectorias laborales de jóvenes. Políticas, instituciones, dispositivos y subjetividades. Programa de estudios sobre juventud, educación y trabajo. PREJET-IDES. Buenos Aires.

JANOSCHKA, M. (2002). El nuevo modelo de la ciudad latinoamericana: fragmentación y privatización. EURE, 85.

. (2006). El modelo de ciudad latinoamericana. Privatización y fragmentación del espacio urbano de Buenos Aires: el caso Nordelta. En M. Welch (Ed.), Buenos Aires a la deriva. Transformaciones urbanas recientes (pp. 96-131). Buenos Aires: Biblos.

KAPLAN, C. (2005). Subjetividad y educación. ¿Quiénes son los adolescentes y jóvenes, hoy? En M. KRICHESKY (Comp.), Adolescentes e inclusión educativa: un derecho en cuestión. Buenos Aires: Centro de Publicaciones Educativas y Material Didáctico, Fundación SES. . (2009). Violencia escolar bajo sospecha. Buenos Aires: Miño y Dávila.

KAWULICH, B. (2005). La observación participante como método de recolección de datos. Forum: qualitative social research, 6(2), 1-32.

LACARRIEU, M. y THUILlIER, G. (2001). Las urbanizaciones privadas en Buenos Aires y su significación. Perfiles Latinoamericanos: revista de la Facultad Latinoamericana de Ciencias Sociales, Sede México, (19), 83-113.

LACLAU, E. (1990). Nuevas reflexiones sobre la revolución de nuestro tiempo. Buenos Aires: Nueva Visión.

LeDESMA, L. (2011). El Almamula: entre el terror, el incesto y la violencia de género (Segunda Parte). Question, 1(31).

LeVI, G. y SchmitT, J. C. (1996). Historia de los jóvenes. Madrid: Taurus.

Machado Pais, J. (2007). Chollos, chapuzas, changas: Jóvenes, trabajo precario y futuro (No. 331.5 M3). México, D. F.: Universidad Autónoma Metropolitana. Unidad Azcapotzalco. 
Malizia, M. y PaOlasso, P. (2009). Countries y barrios privados en Yerba Buena, Gran San Miguel de Tucumán, Argentina: nuevas formas de expansión urbana. Estudios Demográficos y Urbanos, 24(3), 583-613.

MANNHEIM, K. y SÁNCHEZ DE LA YNCERA, I. (1993). El problema de las generaciones. Reis, (62), 193-242.

Marradi, A., Archenti, N. y Piovani, J. (2010). Metodología de las ciencias sociales. Buenos Aires: Cengage Learning.

Martin-Criado, E. (1998). Producir la juventud. Crítica de la sociología de la juventud. Madrid: Istmo.

MAYER, L. (2007). Juventud y democracia: una aproximación a la relación de los jóvenes de la ciudad de Buenos Aires con las instituciones estatales. En Actas electrónicas $1^{\circ}$ Reunión Nacional de Investigadores en Juventudes. La Plata, Red de Investigadores en Juventudes ArgentinaDINAJU.

Meyer. K. y BÄHR, J. (2001). Condominios in Greater Santiago de Chile and their impact on the urban structure. Die Erde, 132(3), 293-321.

MirAndA, A. (2008). Los jóvenes, la educación secundaria y el empleo a principios del siglo XXI. Revista de Trabajo, 4(6), 185-198.

Molina, G. y Maldonado, M. (2011). Interpelaciones a la escuela desde sexualidades diferentes: notas etnográficas con estudiantes secundarios. En D. Milstein, A. Clemente y M. Dantas-Whitney (Eds.), Encuentros etnográficos con niñ@s y adolescentes. Entre tiempos y espacios compartidos (pp. 121-141). Buenos Aires: Miño \& Dávila.

MutuverríA, M. (2014). La clave generacional de Mannheim en la participación política de jóvenes de La Plata. Revista Question, 41.

. (2017). Juventud y participación política: la condición juvenil en el peronismo platense contemporáneo. (Tesis Doctoral). Universidad Nacional de General Sarmiento, Buenos Aires, Argentina.

. (2020). Juventud y política en Argentina: una interpretación del peronismo desde el concepto de generación de Karl Mannheim. Revista Mexicana de Sociología, 83 (en prensa).

Pérez, P., Deleo, C. y Fernández Massi, M. (2013). Desigualdades sociales en trayectorias laborales en la Argentina. Revista Latinoamericana de Población, 7(13).

Rodríguez Chumillas, I. y Mollá Ruiz Gómez, M. (2002). Urbanizaciones cerradas en Puebla y Toluca. En L. F. CABRALES (Ed.), Latinoamérica: países abiertos, ciudades cerradas (pp. 511-548). Guadalajara: Universidad de Guadalajara-UNESCO. 
SAUTU, R. et al. (2005). Manual de metodología: construcción del marco teórico, formulación de los objetivos y elección de la metodología. Buenos Aires: Clacso.

SegurA, R. y Chaves, M. (2019). Modos de habitar: localización, tipo residencial y movilidad cotidiana en el Gran La Plata. En M. DI Virgilio y M. Perelman (Eds.), Disputas por el espacio urbano. Desigualdades persistentes y territorialidades emergentes. Buenos Aires: Biblos.

SVAmPA, M. (2001). Los que ganaron. La vida en los countries y barrios privados. Buenos Aires: Biblos. - (2002). Los riesgos impensados del paraíso. Revista Enfoques Alternativos.

THUILLIER, G. (2005). El impacto socio-espacial de las urbanizaciones cerradas: el caso de la Región Metropolitana de Buenos Aires. EURE, 31(939), 520 .

Tomasini, M. E., Domínguez, L. y Peralta, H. (2014). Sentidos de la violencia en estudiantes de escuelas secundarias: Consideraciones desde la investigación cualitativa. Diálogos Pedagógicos, 12(23), 41-58.

Vasilachis De Gialdino, I. (1993). Métodos cualitativos. Argentina: Centro Editor de América Latina.

Vessuri, H. (1992). Las ciencias sociales en la Argentina: diagnóstico y perspectivas. En E. OTEIZA (Comp.), La política de investigación científica y tecnológica argentina. Historia y perspectivas. Buenos Aires: Bibliotecas Universitarias del Centro Editor de América Latina.

VIDAL KoppmanN, S. (2002). Nuevas fronteras intraurbanas: de los barrios cerrados a los pueblos privados. Buenos Aires, Argentina. En F. CABRAles BARAJAS (Comp.), Latinoamérica: países abiertos, ciudades cerradas (pp. 261-286). Guadalajara: Universidad de GuadalajaraUNESCO.

Vommaro, P. A. (2016). Hacia los enfoques generacionales e intergeneracionales: tensiones y perspectivas en las políticas públicas de juventud en América Latina. Revista Latinoamericana de Estudios de Familia, 8, 119-135. 